\title{
EFEITO DOS TRATAMENTOS FÍSICOS E QUÍMICOS NO RESÍDUO DE LIXADEIRA DO ALGODÃO
}

\author{
Effects of physical and chemical treatments in cotton textile mill waste
}

\author{
Juliana dos Santos ${ }^{1}$, Ana Luisa Aguiar de Castro², Paulo César de Aguiar Paiva ${ }^{3}$, Vera Lúcia Banys ${ }^{4}$
}

\begin{abstract}
RESUMO
O experimento foi conduzido no Departamento de Zootecnia (UFLA) e no Laboratório de Alimentos (UNIFENAS), com o objetivo de avaliar o valor nutritivo do resíduo de lixadeira do algodão pela composição bromatológica (PB, FDN, FDA) e pela degradabilidade da MS e da FDN. Os tratamentos foram: T1 - in natura (IN); T2 - pressão e vapor $\left(127^{0} \mathrm{C} / 1,5 \mathrm{kgf} / \mathrm{cm}^{2} / 35 \mathrm{~min} ; \mathrm{PV}\right)$; T3 $4 \%$ hidróxido de sódio (por 24 horas; $\mathrm{NaOH})$; $\mathrm{T} 4-3 \%$ uréia (por 28 dias; $\mathrm{U}$ ); $\mathrm{T} 5-4 \% \mathrm{NaOH}+3 \%$ uréia $(\mathrm{NaOH} / \mathrm{U}) ; \mathrm{T} 6-\mathrm{PV}+4 \%$ $\mathrm{NaOH}(\mathrm{PV} / \mathrm{NaOH}) ; \mathrm{T} 7-\mathrm{PV}+3 \%$ uréia $(\mathrm{PV} / \mathrm{U})$. Pelos resultados referentes à composição química, conclui-se que os tratamentos associados foram mais eficientes em aumentar o valor nutritivo do resíduo, sendo o tratamento $\mathrm{NaOH} / \mathrm{U}$ o que apresentou os melhores resultados para PB, FDN e FDA. Os maiores valores para a degradabilidade efetiva da MS foram verificados para o resíduo tratado com $\mathrm{PV}, \mathrm{U}, \mathrm{NaOH} / \mathrm{U}, \mathrm{PV} / \mathrm{NaOH}, \mathrm{PV} / \mathrm{U}$, que também apresentaram maior fração solúvel e menor fração insolúvel potencialmente degradável (b). Os tratamentos U, PV/NaOH e PV/U apresentaram as maiores de degradabilidade efetiva da FDN e maior fração solúvel. Os tratamentos associados aumentaram a degradabilidade e o valor nutritivo do resíduo de lixadeira do algodão.
\end{abstract}

Termos para indexação: Hidróxido de sódio, pressão e vapor, uréia, resíduo industrial.

\section{ABSTRACT}

The experiment was carried out at the Department of Animal Science of the Universidade Federal de Lavras and at the Food Laboratory at the Universidade José do Rosário Vellano (UNIFENAS), with the objective to evaluate the nutritive value of cotton textile mill waste using chemical composition (DM, CP, NDF, ADF) and ruminal degradability of the dry matter and NDF. The treatments were: T1 - in natura residue (IN); T2 - residue submitted to the pressure and steam treated $\left(127^{\circ} \mathrm{C} / 1,5\right.$ $\mathrm{kgf} / \mathrm{cm}^{2} / 35$ "; PS); T3 - 4\% sodium hydroxide treated residue (four 24 hours; $\mathrm{NaOH}$ ); $\mathrm{T} 4-3 \%$ urea treated residue (for 28 days; $\mathrm{U})$; $55-4 \% \mathrm{NaOH}+3 \%$ urea treated residue $(\mathrm{NaOH} / \mathrm{U})$; $\mathrm{T} 6$ - pressure and steam $+4 \% \mathrm{NaOH}$ treated residue $(\mathrm{PS} / \mathrm{NaOH}) ; \mathrm{T} 7-$ pressure and steam $+3 \%$ urea treated residue (PS/U). The results obtained in the chemical composition can allow concluding that combined treatments improved the nutritive value of the residue, as the $\mathrm{NaOH} / \mathrm{U}$ treatment showed better results of $\mathrm{CP}$, NDF, ADF. In the degradability experiment, it may be concluded that PS, $\mathrm{U}, \mathrm{NaOH} / \mathrm{U}, \mathrm{PS} / \mathrm{NaOH}$ and $\mathrm{PS} / \mathrm{U}$ treatments were efficient in increasing effective degradability of DM, also resulted higher dry matter soluble fraction (a) and lower insoluble potentially degradable fraction (b). The treatments $\mathrm{U}, \mathrm{PS} / \mathrm{NaOH}$ and $\mathrm{PS} / \mathrm{U}$ had higher values of effective degradability of NDF and higher soluble fraction (a). The combined treatments increased the degradability and nutritive value of cotton textile mill waste, and combined treatments with urea had the better results.

Index terms: Degradability, sodium hydroxide, pressure and steam, urea, industrial by-products.

(Recebido para publicação em 14 de abril de 2003 e aprovado em 8 de setembro de 2003)

\section{INTRODUÇÃO}

Os subprodutos agroindustriais e culturais podem ser considerados alternativas para a alimentação de animais, dos quais os ruminantes, pelas características do seu aparelho digestivo, são os mais aptos a utilizarem tais produtos. O resíduo de lixadeira, resultante do beneficiamento têxtil do algodão, é um alimento rico em constituintes de parede celular, tem baixa digestibilidade e é pobre em proteínas e mine rais, representando sério problema para a indústria têxtil devido ao grande excedente acumulado no pátio das indústrias e pelo fato de ser altamente poluidor do meio ambiente devido à baixa taxa de decomposição no meio. Esse resíduo deve ser submetido a tratamentos prévios que melhorem seu valor nutritivo para ser utilizado na alimentação de ruminantes (ROSA e FADEL, 2001).

\footnotetext{
1. Mestre em Nutrição de Ruminantes pela Universidade Federal de Lavras/UFLA - Caixa Postal 37 - 37200-000 - Lavras, MG - jsantos@ufla.br 2. Mestre em Nutrição de Ruminantes pela UFLA - alacbr@yahoo.com.br

3. PhD em Zootecnia, Professor Titular do Departamento de Zootecnia da UFLA - pcapaiva@ufla.br

4. Dra. em Zootecnia, Professora do Departamento de Ciências Agrárias da UNIFENAS - verabanys@uol.com.br
} 
Por ser um processo simples, o aquecimento sob pressão e vapor tem despertado bastante a atenção dos pesquisadores. Vários trabalhos têm sido realizados no sentido de melhorar o aproveitamento dos volumosos de baixa qualidade com esse tratamento, que tem como princípio submeter o material a elevadas pressões e temperaturas, durante determinado período de tempo, seguidas de rápida descompressão, resultando em melhoria na digestibilidade pela redução da fração fibrosa (MELLO JÚNIOR, 1987).

Segundo Bose e Martins Filho (1984), os tratamentos químicos consistem em utilizar substâncias capazes de dissolver os componentes da forragem mais resistentes à digestão ruminal. Além de existirem vários compostos químicos, esses devem apresentar determinadas características para que seu uso possa ser recomendado em larga escala. $\mathrm{O}$ tratamento químico com hidróxido de sódio tem sido utilizado para quebrar o composto lignocelulósico das forragens e aumentar proporcionalmente seus componentes nutritivos (ALMASRI e GUENTHER, 1999).

A amonização de volumosos de baixa qualidade, que pode ter custo reduzido com a utilização de uréia, promove o aumento das degradabilidades da matéria seca e dos constituintes da parede celular (PIRES, 2000).

Objetivou-se avaliar o valor nutritivo do resíduo do beneficiamento têxtil do algodão, na forma de resíduo de lixadeira, tratado com pressão e vapor e/ou hidróxido de sódio e/ou uréia, pela composição bromatológica e a degradabilidade da matéria seca e da fibra em detergente neutro.

\section{MATERIAL E MÉTODOS}

O experimento foi conduzido no período de junho a dezembro de 2002 no Laboratório de Alimentos da Universidade José do Rosário Vellano (UNIFENAS) e no Departamento de Zootecnia (DZO) da Universidade Federal de Lavras (UFLA). Utilizou-se o resíduo da tecelagem do algodão (resíduo de lixadeira) proveniente da Companhia Industrial Jauense, Jaú/SP. O resíduo foi submetido aos seguintes tratamentos: $\mathrm{T} 1$ - in natura (IN); T2 - ação de pressão e vapor $\left(127^{\circ} \mathrm{C} / 35 \mathrm{~min}\right.$ atingindo $1,5 \mathrm{kgf} / \mathrm{cm}^{2}$; PV); T3 - 4\% de hidróxido de sódio (por 24 horas; $\mathrm{NaOH}$ ); $\mathrm{T} 4-3 \%$ de uréia (por 28 dias; U); T5 $-4 \%$ de hidróxido de sódio mais $3 \%$ de uréia $(\mathrm{NaOH} / \mathrm{U})$; T6 - ação de pressão e vapor mais $4 \%$ de hidróxido de sódio (PV/NaOH); T7 - ação de pressão e vapor mais $3 \%$ de uréia (PV/U).

Para o tratamento com PV, o resíduo foi autoclavado com temperatura de $127^{\circ} \mathrm{C} / 1,5 \mathrm{kgf} / \mathrm{cm}^{2}$ por $35 \mathrm{mi}$ nutos; em seguida, foi separado para receber os outros tratamentos. Para os tratamentos $\mathrm{NaOH}$ e U, o material foi espalhado em lona e pulverizado com solução de $4 \%$ de hidróxido de sódio ou 3\% de uréia, base na matéria seca. A diluição das soluções foi feita na relação de 1:1 (V/P em L/kg). O tratamento $\mathrm{U}$ foi acondicionado em silos de PVC durante 28 dias e o tratamento com $\mathrm{NaOH}$ foi acondicionado em sacos negros de PVC de 100 litros durante 24 horas. Para o tratamento com NaOH/U, primeiro foi feita a aplicação do hidróxido de sódio, e após 24 horas, a aplicação da uréia e o acondicionamento em silos de PVC por 28 dias. Para o tratamento $\mathrm{PV} / \mathrm{NaOH}$ e $\mathrm{PV} / \mathrm{U}$, o material, já autoclavado, foi espalhado em lona e pulverizado com solução de $4 \%$ de $\mathrm{NaOH}$ ou 3\% de uréia, seguindo a diluição dos tratamentos com apenas $\mathrm{NaOH}$ e $\mathrm{U}$.

Decorrido o prazo de ação dos tratamentos, foram tomadas amostras do resíduo para a análise bromatológica. $\mathrm{O}$ material foi submetido às análises de matéria seca (MS), fibra em detergente neutro (FDN), fibra em detergente ácido (FDA), hemicelulose (por diferença entre FDN e FDA) e proteína bruta (PB), de acordo com as técnicas descritas por Silva (1990). O ensaio de degradabilidade foi conduzido segundo as recomendações de Nocek (1988) utilizando três vacas da raça Jersey, providas de cânula ruminal, não-lactantes, distribuídas em delineamento inteiramente casualizado com uso de sacos de náilon medindo $6 \times 8 \mathrm{~cm}$, com porosidade média de $50 \mu \mathrm{m}$. As incubações foram feitas no tempo 0, 4, $8,12,24,36,48,72$ e 96 horas em ordem seqüencial, inserindo primeiro o tempo de 96 horas. Após a incubação, os sacos foram lavados em água corrente por 15 minutos. Os dados obtidos por diferença foram ajustados por regressão não-linear pelo método de Gauss-Newton, a equação proposta por Ørskov e McDonald (1979). Observado o efeito significativo entre os tratamentos na análise de variância, as médias dos tratamentos foram comparadas pelo teste Scott e Knott, contido no programa estatístico SAEG (EUCLYDES, 1997), ao nível de 5\% de probabilidade.

\section{RESULTADOS E DISCUSSÃO}

Os valores de PB, FDN e FDA do resíduo de lixadeira do algodão estão no Quadro 1. Os tratamentos associados foram mais eficientes em melhorar o valor nutritivo do resíduo, sendo o tratamento $\mathrm{NaOH} / \mathrm{U}$ superior aos demais, por apresentar maior valor de $\mathrm{PB}$ e maiores reduções nas frações de FDN e FDA. O aumento no teor de PB do resíduo pode ser atribuído ao nitrogênio não-protéico oriundo da amônia liberada como resultado da hidrólise da uréia adicionada. Os

Ciênc. agrotec., Lavras, v. 28, n. 4, p. 919-923, jul./ago., 2004 
tratamentos com álcalis $(\mathrm{NaOH}$ e $\mathrm{U})$ atuam modificando o complexo formado entre a celulose, a hemicelulose e lignina, tornando-o mais solúvel e mais acessível à hidrolise enzimática. Dessa forma, o maior declínio na concentração da fração FDN pode ser explicado pela ação desses compostos (GRANZIN e DRYDEN, 2003).

A atuação isolada da PV e U mostrou-se ineficiente em reduzir as frações da FDN e FDA, podendo estar relacionada à baixa pressão utilizada no tratamento PV e à baixa alcalinidade da uréia, como observou Almeida (2000).

Os valores de degradabilidade potencial, efetiva, fração solúvel "a", fração insolúvel potencialmente degradável "b" e taxa de degradação "c" da fração "b" da MS e FDN do resíduo de lixadeira do algodão estão no Quadro 2. As frações solúvel "a" e insolúvel potencialmente degradável e a degradabilidade efetiva da MS foram afetadas significativamente pelos tratamentos $(p<0,05)$. O aumento na degradabilidade efetiva pode ser atribuído ao efeito dos tratamentos sobre a parede celular do resíduo, principalmente pe- lo aumento no percentual de $\mathrm{PB}$, pois a amônia gerada pela hidrólise da uréia atua nas ligações físicas e químicas entre lignina, celulose e hemicelulose da parede celular, tornando-as mais acessíveis ao ataque dos microrganismos do rúmen, aumentando, assim, a degradabilidade do resíduo (PRESTON, 1995).

Observou-se efeito significativo $(\mathrm{p}>0,05)$ dos tratamentos para as variáveis fração solúvel "a" e degradabilidade efetiva quanto ao desaparecimento da fração FDN. Os maiores valores de degradabilidade efetiva foram encontrados para os tratamentos $\mathrm{U}$, $\mathrm{PV} / \mathrm{NaOH}$ e $\mathrm{PV} / \mathrm{U}$, que foram significativamente superiores ao demais tratamentos, refletindo o aumento da fração solúvel "a" e redução ainda que não significativa da fração insolúvel potencialmente degradável "b". A eficiência do tratamento com uréia em aumentar a degradabilidade da FDN confirma relatos da literatura (MATTOS, 1992; PIRES, 2000), os quais associam a melhora da digestibilidade à solubilização parcial da hemicelulose e afrouxamento da parede celular.

QUADRO 1 - Composição do resíduo de lixadeira do algodão in natura e efeito dos tratamentos no percentual dos nutrientes, em base de matéria seca.

\begin{tabular}{|c|c|c|c|c|}
\hline \multirow{2}{*}{ Tratamentos } & \multicolumn{4}{|c|}{ Nutrientes $(\%)^{*}$} \\
\hline & PB & FDN & FDA & HEMI \\
\hline IN (in natura) & $0,87^{\mathrm{d}}$ & $95,17^{\mathrm{a}}$ & $91,51^{\mathrm{a}}$ & 3,66 \\
\hline PV (pressão e vapor) & $2,18^{\mathrm{c}}$ & $93,38^{\mathrm{a}}$ & $90,17^{\mathrm{a}}$ & 3,21 \\
\hline NaOH (hidróxido de sódio) & $0,73^{\mathrm{d}}$ & $92,54^{\mathrm{a}}$ & $86,23^{\mathrm{b}}$ & 6,31 \\
\hline U (uréia) & $2,56^{\mathrm{c}}$ & $92,76^{\mathrm{a}}$ & $87,85^{\mathrm{a}}$ & 4,90 \\
\hline $\mathrm{NaOH} / \mathrm{U}(\mathrm{NaOH}+$ uréia) & $9,53^{\mathrm{a}}$ & $88,99^{\mathrm{b}}$ & $82,89^{b}$ & 6,10 \\
\hline $\mathrm{PV} / \mathrm{NaOH}$ (Pressão e vapor $+\mathrm{NaOH})$ & $2,50^{\mathrm{c}}$ & $89,42^{\mathrm{b}}$ & $84,32^{b}$ & 5,09 \\
\hline PV/U (Pressão e vapor + uréia) & $6,31^{b}$ & $91,28^{\mathrm{b}}$ & $87,91^{\text {a }}$ & 3,37 \\
\hline $\mathrm{CV}(\%)$ & 7,51 & 2,371 & 3,036 & 49,68 \\
\hline
\end{tabular}

*Médias seguidas de mesma letra na coluna não diferem estatisticamente entre si pelo teste Scott-Knott ao nível de $5 \%$ de probabilidade. 
QUADRO 2 - Valores médios para os coeficientes de degradação "a” (fração solúvel), "b" (fração insolúvel potencialmente degradável) e "c" (taxa de degradação da fração b), degradabilidades potencial e efetiva e coeficiente de determinação da matéria seca do resíduo de lixadeira submetido aos tratamentos físicos e químicos.

\begin{tabular}{|c|c|c|c|c|c|c|}
\hline Tratamentos & a $(\%)$ & b $(\%)$ & c $(\% / h)$ & DP & $\mathbf{D E}^{*}$ & $\mathbf{R}^{2}$ \\
\hline \multicolumn{7}{|c|}{ Matéria Seca } \\
\hline In natura & $8,04^{\mathrm{d}}$ & $90,00^{\mathrm{a}}$ & 3,33 & 98,04 & $43,87^{\mathrm{b}}$ & 95,63 \\
\hline Pressão e vapor & $19,63^{\mathrm{b}}$ & $78,33^{\mathrm{c}}$ & 3,00 & 97,97 & $49,01^{\mathrm{a}}$ & 93,85 \\
\hline NaOH (hidróxido de sódio) & $12,57^{\mathrm{c}}$ & $83,33^{\mathrm{b}}$ & 3,33 & 95,90 & $45,67^{\mathrm{b}}$ & 95,83 \\
\hline Uréia & $21,47^{\mathrm{b}}$ & $76,67^{\mathrm{c}}$ & 3,33 & 98,13 & $51,95^{\mathrm{a}}$ & 93,15 \\
\hline $\mathrm{NaOH}+$ uréia & $23,32^{\mathrm{a}}$ & $75,00^{\mathrm{c}}$ & 3,33 & 98,32 & $53,18^{\mathrm{a}}$ & 92,85 \\
\hline Pressão e vapor $+\mathrm{NaOH}$ & $23,75^{\mathrm{a}}$ & $75,00^{\mathrm{c}}$ & 3,00 & 98,75 & $51,38^{\mathrm{a}}$ & 94,63 \\
\hline Pressão e vapor + uréia & $23,72^{\mathrm{a}}$ & $75,00^{\mathrm{c}}$ & 3,00 & 98,72 & $51,85^{\mathrm{a}}$ & 94,30 \\
\hline $\mathrm{CV}(\%)$ & 9,66 & 3,38 & 18,09 & 1,59 & 6,58 & 1,20 \\
\hline \multicolumn{7}{|c|}{ Fibra em Detergente } \\
\hline In natura & $3,98^{\mathrm{b}}$ & 93,33 & 0,9 & 97,32 & $17,55^{\mathrm{b}}$ & 73,08 \\
\hline Pressão e vapor & $6,62^{b}$ & 91,67 & 0,8 & 98,28 & $19,19^{\mathrm{b}}$ & 75,10 \\
\hline NaOH (hidróxido de sódio) & $5,52^{\mathrm{b}}$ & 91,67 & 0,7 & 97,19 & $17,07^{\mathrm{b}}$ & 67,96 \\
\hline Uréia & $11,38^{\mathrm{a}}$ & 68,67 & 1,3 & 80,05 & $23,43^{\mathrm{a}}$ & 39,44 \\
\hline $\mathrm{NaOH}+$ uréia & $6,93^{\mathrm{b}}$ & 90,00 & 0,8 & 96,93 & $19,66^{\mathrm{b}}$ & 60,97 \\
\hline Pressão e vapor $+\mathrm{NaOH}$ & $12,42^{\mathrm{a}}$ & 85,00 & 0,8 & 97,42 & $23,38^{\mathrm{a}}$ & 47,89 \\
\hline Pressão e vapor + uréia & $10,32^{\mathrm{a}}$ & 88,33 & 1,0 & 98,65 & $25,47^{\mathrm{a}}$ & 70,66 \\
\hline $\mathrm{CV}(\%)$ & 28,92 & 14,44 & 32,875 & 12,7 & 11,26 & 15,75 \\
\hline
\end{tabular}

*Médias seguidas de mesma letra, na coluna, não diferem estatisticamente entre si pelo teste Scott-Knott ao nível de $5 \%$ de probabilidade.

\section{CONCLUSÕES}

Com base nos resultados, os tratamentos associados foram eficientes em melhorar a degradabilidade da matéria seca e da fibra em detergente neutro e o valor nutritivo do resíduo de lixadeira do algodão, sendo as associações com uréia as mais eficientes.

\section{AGRADECIMENTOS}

À Companhia Industrial Jauense - Jaú/SP, pela doação do resíduo de lixadeira do algodão.

\section{REFERÊNCIAS BILIOGRÁFICAS}

AL-MASRI, M. R.; GUENTHER, K. D. Changes in digestibility and cell-wall constituents of some agricultural by-products and urea treatments. Radiation Physics and Chemistry, Oxford, v. 55, n. 3, p. 323-329, July 1999.

ALMEIDA, O. C. de. Caracterização e cinética ruminal de resíduos têxtil da fibra de algodão submetido a diferentes tratamentos. 2000. 71 p. Dissertação 
(Mestrado em Zootecnia) - Universidade Federal de Lavras, Lavras, 2000.

BOSE, M. L.; MARTINS FILHO, J. G. O papel dos resíduos agro industriais na alimentação dos ruminantes. Informe agropecuário, Belo Horizonte, v. 10, n. 119, p. 3-7, nov. 1984.

EUCLYDES, R. F. Manual de utilização do programa SAEG - Sistema para Análise Estatísticas e Genéticas. 2. ed. Viçosa: UFV, 1997. 150 p.

GRANZIN, B. C.; DRYDEN, G. M. C. H. Effects of alkalis, oxidants and urea on the nutritive value of Rhodes grass (Chloris gayana cv. Callide). Animal feed Science and Technology, Amsterdam, v. 103, n. 1/4, p. 113-122, Jan. 2003.

MATTOS, W. Alimentos volumosos: tratamentos para elevar o valor nutritivo. Piracicaba: FEALQ, 1992. 224 p.

MELLO JÚNIOR, C. A. Efeito do tratamento com pressão e vapor sobre a fermentação "in vitro" do bagaço de cana-de-açúcar (Saccharum sp. L.). 1987. 100 f. Dissertação (Mestrado em Zootecnia) - Escola
Superior de Agricultura Luiz de Queiroz, Piracicaba, 1987.

NOCEK, J. E. In situ and others methods to estimate ruminal protein and energy digestibility: a review. Journal of Dairy Science, Champaign, v. 71, n. 8, p. 2051-2059, Aug. 1988.

ØRSKOV, E. R.; MCDONALD, I. The estimation of protein degradability in the rumen from incubation measurements weighted according to rate of passage. Journal of Agricultural Science, Cambridge, v. 92, n. 2, p. 499-503, Apr. 1979.

PIRES, A. J. V. Bagaço de cana-de-açúcar tratado com amônia e/ou, sulfeto de sódio para novilhas em crescimento. 2000. 65 f. Tese (Doutorado) - Universidade Federal de Viçosa, Viçosa, 2000.

PRESTON, T. R. Technologies for improving the use of renewable natural resources. In: Tropical animal feeding: a manual for research workers. New York: FAO, 1995. 124 p.

ROSA, B.; FADEL, R. Uso de amônia anidra e de uréia para melhorar o valor alimentício de forragens conservadas. Maringá: [s.n.], 2001.

SILVA, D. J. Análises de alimentos: métodos químicos e biológicos. Viçosa: UFV, 1990. 165 p. 